\title{
Venous thromboembolism and cancer risk
}

\author{
Per Sandén ${ }^{1,3}$ (1) Peter J. Svensson ${ }^{2}$ Anders Själander ${ }^{1}$
}

Published online: 13 August 2016

(C) The Author(s) 2016. This article is published with open access at Springerlink.com

\begin{abstract}
Cancer increases the risk of venous thromboembolism (VTE) and about $20 \%$ of all VTE are associated with cancer. VTE can also be used as a marker for occult cancer. The objective was to examine the correlation between VTE and cancer regarding predictors for a subsequent cancer diagnosis. Patients treated for VTE between January 1st 2006 and December 31th 2011 were extracted from the Swedish national quality register AuriculA and crossmatched with the Swedish National Patient Register. In total 7854 patients corresponding to 14284 treatments years were examined. Primary VTE was found in 6451 patients, with 3936 first and 2515 recurrent VTE. There were 1403 patients with secondary VTE. After a first or recurrent primary VTE the incidence of cancer diagnose was high being 9.4-10.0\% the first year compared to $2.7-2.5 \%$ during the second year. Cancer in the digestive organs was the most common type of cancer among those with first primary VTE with $19.2 \%$ of diagnoses. In multivariable analysis age was found to increase the risk of cancer diagnosis after both first and recurrent primary VTE HR 1.02 (CI 1.02-1.03) and HR 1.02 (CI 1.01-1.03). For a first primary VTE anemia HR 2.13 (CI 1.48-3.08) and male sex HR 1.38 (CI 1.09-1.76) increased the risk while hypertension HR 0.74 (0.57-0.96), dementia HR 0.30 (CI 0.10-0.95) and history of major bleeding HR 0.52 (CI
\end{abstract}

Per Sandén

sanden.per@gmail.com

1 Department of Public Health and Clinical Medicine, Umeå University, Sundsvall, Sweden

2 Department for Coagulation Disorders, University of Lund, Malmö, Sweden

3 Department of Clinical Sciences, Karolinska Institutet, Danderyd Hospital, Stockholm, Sweden
0.28-0.97) reduced the risk of a subsequent cancer diagnosis. There is a substantial proportion of patients being diagnosed with cancer the first year after a primary VTE, anaemia and male sex confers an increased risk.

Keywords Venous thromboembolism - Cancer . Warfarin · VTE

\section{Background}

Cancer is known to increase the risk of venous thromboembolism (VTE) and about $20 \%$ of all VTE are associated with cancer $[1,2]$. Patients with cancer have a four to seven times increased risk of developing VTE and chemotherapy increases the risk further [3]. Tumours can express different procoagulant molecules and modify the expression of tissue factor which is one explanation to the increased risk of developing VTE among cancer patients [4]. Some tumours compress vessels altering blood flow or create damages to the vessel wall through intravascular growth increasing the risk for thrombosis.

VTE is also a marker for occult cancer [5], up to $10 \%$ of patients with a first VTE have a subsequent cancer diagnosis within the first year [6, 7]. The risk of VTE differ between different cancer types [8], where cancer in the pancreas, kidney, stomach, ovary, brain and lymphomas have shown the strongest correlation to venous thrombosis. After a first VTE recurrence is relatively common and a concurrent cancer increases that risk [9]. Recurrent VTE has also previously been shown to increase the risk for a subsequent cancer diagnosis [10].

The aim of this study was to examine the correlation between VTE and cancer regarding predictors for a subsequent cancer diagnosis. 


\section{Materials and methods}

This is a retrospective study using secondary databases.

\section{Registries}

AuriculA [11] was founded in 2006 and is a Swedish national quality register for atrial fibrillation (AF) as well as all patients on oral anticoagulation regardless of treatment indication. The register now includes over 125.000 patients and more than 7.000.000 INR values. Of all patients on oral anticoagulation in AuriculA, $19 \%$ are treated due to a VTE. Approximately $50 \%$ of all patients on warfarin in Sweden are included in AuriculA, mainly in whole regions with no apparent selection bias. Everything done with the patients in the anticoagulation centres in everyday clinical practice is recorded and transferred to the quality register automatically once every $24 \mathrm{~h}$, provided that the patient has not declined to participate. AuriculA also provides a clinical decision tool, aiding in the dosage of warfarin using a dosing algorithm.

The Swedish National Patient Register [12] contains information about hospital admissions as well as visits in outpatient clinics in Sweden for all patients with a Swedish personal identity number. The register was launched in 1964, but complete coverage began in 1987. Currently, more than $99 \%$ of all somatic and psychiatric hospital discharges are registered in the NPR. Information in this register includes dates for admission and discharge, ICD10 codes for primary and secondary diagnoses as well as surgical procedures, age and sex category.

The national quality register AuriculA was matched with the NPR at the Swedish national board of health and welfare using personal identity numbers and a common database was created which was anonymised. From this database patients treated with warfarin due to VTE between January 1́st 2006 and December 31th 2011 with available information about background characteristics in the NPR were extracted.

\section{Patient population}

In total 8831 patients with a first or recurrent VTE were retrieved. 8112 remained in the study after exclusion of those with a prior cancer diagnosis $(n=719)$. We analysed secondary VTE defined as patients with diagnosis of fracture or surgery within 6 months prior to warfarin initiation $(n=1403)$ separately. Patients with primary VTE with diagnosis between 90 days and 1 week before warfarin treatment were excluded from analysis $(n=258)$.

\section{Statistical analysis plan}

A first VTE was defined as a first time diagnosis of a VTE within 1 week before start of warfarin treatment. Recurrent venous thrombosis was defined as presence of a previous
VTE diagnosis 90 days or more before start of warfarin treatment due to the recurrent VTE. During the study period, almost all patients with VTE were treated with warfarin in Sweden, new oral anticoagulants were not available for this indication by then.

ICD10 codes were used for characterising background factors and new cancer diagnoses (Appendix).

Background characteristics were presented descriptively and differences between subgroups were tested with t-tests and $\mathrm{X}^{2}$-tests. Proportion diagnosed with cancer was described as diagnoses per 100 observation years expressed as percent.

Correlation between background factors and cancer diagnosis was analysed using multivariate cox regression analysis. Covariates were selected based on biological plausibility using ICD 10 codes defined in Appendix with the exemption of covariates with low a probability of registration in NPR.

Data was analysed using SPSS Statistics (Version 22; SPSS Inc., IBM Corporation, NY, USA), Confidence intervals $(\mathrm{CI})$ are $95 \% \mathrm{p}<0.05$.

\section{Results}

In total 3936 patients with a first, 2515 with a recurrent primary venous thrombosis and 1403 patients with a VTE secondary to surgery or fracture were examined, and followed for 14,284 patient years. Those with a recurrent thrombosis were older, 68,6 compared to 66,3 years $(\mathrm{p}=<0.001)$, and had a higher proportion of previous diseases (Table 1).

The incidence of cancer diagnosis during the first year after initiation of warfarin was $9.4 \%$ per year for those with a first VTE and $10.0 \%$ for those with a recurrent VTE (Table 2). During the second year the incidence of a new cancer diagnose was 2.7 and $2.5 \%$ for those with a first or recurrent VTE, respectively.

After a secondary VTE, $2.5 \%$ per year and $0.8 \%$ per year had a new cancer diagnosis during the first or second year.

Almost all patients in the study, $96 \%$, were treated for venous thrombosis in the leg or lung.

The most common cancer type for those with a first VTE was cancer in the digestive organs (19.2\%) and cancer in the male genitals for those with recurrent VTE $(23.8 \%)$ (Table 3). Among men cancer in the male genitals was the most common type (35.8\%) of which $96 \%$ were prostate cancer and among women it was cancer in the digestive organs $(19.4 \%)$.

Correlation between a new cancer diagnosis the first year after a VTE and background factors was analyzed using multivariate Cox regression (Table 4). Factors that increased the risk of a cancer diagnosis during the first year for those with a first VTE were age HR 1.03 (1.02-1.03), anemia HR 2.13 (1.48-3.08) and male sex HR 1.38 (1.09-1.76). Hypertension HR 0.74 (0.57-0.96), dementia HR $0.30(0.10-0.95)$ and history of major bleeding HR 0.52 
Table 1 Background characteristics for patients at initiation of warfarin treatment presented as $\mathrm{n}(\%)$
Table 2 Cancer diagnoses displayed as proportion (\%) per observed time with $95 \% \mathrm{CI}$, subdivided in primary VTE (first or recurrent) and VTE secondary to fracture or surgery

\begin{tabular}{lccc}
\hline & First VTE & Recurrent VTE & Secondary VTE \\
& $\mathrm{N}=3936$ & $\mathrm{~N}=2515$ & $\mathrm{~N}=1403$ \\
\hline Start age (SD) & $66.3(15.8)$ & $68.5(15.2)^{* *}$ & $66.4(15.9)$ \\
Sex (female) & $1879(47.7)$ & $1198(47.6)$ & $803(57.2)$ \\
Hypertension & $1297(33.0)$ & $1056(42.0)^{* *}$ & $663(47.3)$ \\
Cardiac failure & $261(6.6)$ & $332(13.2)^{* *}$ & $165(11.8)$ \\
Myocardial infarction & $272(6.9)$ & $288(11.5)^{* *}$ & $137(9.8)$ \\
Stroke/TIA & $405(10.3)$ & $330(13.1)^{* *}$ & $152(10.8)$ \\
Diabetes & $446(11.3)$ & $318(12.6)$ & $193(13.8)$ \\
Thyroid disorder & $203(5.2)$ & $166(6.6)^{*}$ & $138(9.8)$ \\
Chronic pulmonary disease & $286(7.3)$ & $362(14.4)^{* *}$ & $164(11.7)$ \\
Dementia & $100(2.5)$ & $67(2.7)$ & $28(2.0)$ \\
Anaemia & $263(6.6)$ & $258(10.3)^{* *}$ & $180(12.8)$ \\
History of major bleeding & $203(5.2)$ & $217(8.6)^{* *}$ & $150(10.7)$ \\
Renal failure & $120(3.1)$ & $127(5.1)^{* *}$ & $92(6.6)$ \\
Liver failure & $58(1.5)$ & $30(1.2)$ & $28(2.0)$ \\
\hline
\end{tabular}

Difference between first and recurrent VTE

* Significance with $\mathrm{p}<0.05$

** Significance with $\mathrm{p}<0.001$

\begin{tabular}{lccc}
\hline & \multicolumn{2}{l}{ Proportion diagnosed with cancer } \\
\cline { 2 - 4 } & \multicolumn{4}{l}{ Year 1 } & Year 2 & Year 3 \\
\hline Primary VTE combined & $9.6(8.9-10.5)$ & $2.7(2.2-3.2)$ & $2.0(1.5-2.6)$ \\
First & $9.4(8.4-10.5)$ & $2.7(2.1-3.4)$ & $1.9(1.2-2.6)$ \\
Recurrent & $10.0(8.7-11.3)$ & $2.5(1.8-3.3)$ & $2.2(1.3-3.2)$ \\
Secondary VTE & $2.5(1.6-3.5)$ & $0.4(0-0.8)$ & $1.1(0.1-2.1)$ \\
\hline
\end{tabular}

Table 3 Type of cancer diagnosed during the first year after a primary VTE (first or recurrent). Results given as numbers and proportion (\%) of total

\begin{tabular}{lcc}
\hline Localisation & First VTE & $\begin{array}{l}\text { Recurrent VTE } \\
\mathrm{N}=202\end{array}$ \\
\hline Unspecified & $\mathrm{N}=297$ & $40(19.8)$ \\
Male genital organs & $53(17.9)$ & $48(23.8)$ \\
Digestive organs & $57(19.2)$ & $32(15.8)$ \\
Lymphoid hematopoietic and related tissue & $46(15.5)$ & $38(18.8)$ \\
Urinary tract & $37(12.5)$ & $22(10.9)$ \\
Respiratory and intrathoracic organs & $30(10.1)$ & $12(5.9)$ \\
Breast & $20(6.7)$ & $17(8.4)$ \\
Female genital organs & $21(7.1)$ & $10(5.0)$ \\
Eye, brain and other parts of central nervous system & $13(4.4)$ & $5(2.5)$ \\
Skin & $6(2.0)$ & $10(5.0)$ \\
Bone and articual cartilage & $2(0.7)$ & $2(1.0)$ \\
Mesotelial and soft tissue & $3(1.0)$ & $2(1.0)$ \\
Lip, oral cavity and pharynx & $1(0.3)$ & $2(1.0)$ \\
Thyroid and other endocrine glands & 0 & $1(0.5)$ \\
\hline
\end{tabular}

(0.28-0.97) reduced the risk of a subsequent cancer diagnosis. For those with recurrent VTE only age HR 1.02 (1.01-1.03) significantly increased the risk of a new cancer diagnosis. For patients over 45 years old with a first VTE, age HR 1.02 (1.01-1.03), anemia HR 2.18 (1.50-3.16) and male sex HR 1.37 (1.07-1.75) increased the risk of a cancer diagnosis. Hypertension HR 0.73 (0.56-0.95), dementia HR $0.32(0.10-1.00)$ and history 
Table 4 Multiple cox regression of background characteristics and the occurrence of a new cancer diagnosis during the first year after a first or recurrent primary VTE

\begin{tabular}{|c|c|c|c|c|c|c|}
\hline & \multicolumn{3}{|c|}{ First VTE } & \multicolumn{3}{|c|}{ Recurrent VTE } \\
\hline & HR & $\mathrm{p}$ & $95 \% \mathrm{CI}$ & $\mathrm{HR}$ & $\mathrm{p}$ & $95 \%$ CI \\
\hline Start age & 1.03 & $<0.001$ & $1.02-1.03$ & 1.02 & 0.001 & $1.01-1.03$ \\
\hline Sex (male) & 1.38 & 0.008 & $1.09-1.76$ & 1.24 & 0.14 & $0.93-1.66$ \\
\hline Hypertension & 0.74 & 0.02 & $0.57-0.96$ & 1.17 & 0.31 & $0.87-1.57$ \\
\hline Cardiac failure & 1.06 & 0.77 & $0.69-1.64$ & 1.05 & 0.83 & $0.69-1.58$ \\
\hline Myocardial infarction & 0.63 & 0.07 & $0.38-1.04$ & 0.61 & 0.06 & $0.37-1.02$ \\
\hline Stroke/TIA & 0.77 & 0.22 & $0.51-1.16$ & 0.82 & 0.38 & $0.54-1.27$ \\
\hline Diabetes & 1.10 & 0.62 & $0.76-1.58$ & 0.70 & 0.13 & $0.44-1.12$ \\
\hline Thyroid disorder & 1.14 & 0.61 & $0.69-1.87$ & 0.76 & 0.39 & $0.41-1.42$ \\
\hline Chronic pulmonary disease & 1.34 & 0.14 & $0.91-1.99$ & 1.37 & 0.09 & $0.95-1.99$ \\
\hline Dementia & 0.30 & 0.04 & $0.10-0.95$ & 0.99 & 0.99 & $0.44-2.26$ \\
\hline Anaemia & 2.13 & $<0.001$ & $1.48-3.08$ & 1.04 & 0.86 & $0.67-1.63$ \\
\hline History of major bleeding & 0.52 & 0.04 & $0.28-0.97$ & 1.45 & 0.09 & $0.94-2.24$ \\
\hline Renal failure & 1.26 & 0.45 & $0.70-2.27$ & 1.34 & 0.30 & $0.77-2.33$ \\
\hline Liver failure & 0.0 & 0.92 & - & 1.39 & 0.58 & $0.44-4.41$ \\
\hline
\end{tabular}

of major bleeding HR $0.53(0.29-0.99)$ reduced the risk of a subsequent cancer diagnosis.

\section{Discussion}

After a first primary VTE a there is a high rate of cancer diagnosis with $9.4 \%$ per year during the first year and additionally $2.7 \%$ during the second year. For recurrent primary VTE the rate diagnosed with cancer is similar with $10.0 \%$ during the first year, this surpasses the $2.5 \%$ per year after a VTE secondary to fracture or surgery.

These results are well in line with those previously published where Sørenssen et al. [10] found an increased standardized incidence ratio of 2.2-3.2 for a cancer diagnosis the first year after a first or recurrent primary VTE, Prandoni et al. a frequency of 7.6-17.1\% [13] and Sun et al. [14] showing a clearly higher risk of cancer diagnosis after unprovoked VTE compared to a provoked VTE.

Except for rising age, which is a predictor for cancer diagnosis both after a first and recurrent VTE, we found anaemia to be a risk factor for a new cancer diagnosis after a first primary VTE in accordance to results by Trujillo-Santo et al. [15]. Anaemia has also been shown to increase the risk of VTE after cancer diagnosis [16] further supporting this connection. However, anaemia was not identified to be a risk factor for those with recurrent primary thrombosis, which to our knowledge has not been studied before. Those with a previous VTE have had treatment with anticoagulants where potential bleeding sources like tumours in the gastrointestinal tract might already have been discovered, rendering a new cancer diagnosis emerging after a recurrent VTE less likely. The same was true for patients with a history of major bleeding, where the risk of a new cancer diagnosis was reduced after a first but not after recurrent VTE, possibly due to the same mechanism as proposed above for anaemia. Major bleeding could cause immobilization and prolonged hospital stay, which increases the risk of VTE by itself, which also might explain the lower prevalence of new cancer diagnoses in this group.

Male sex increased the risk of obtaining a cancer diagnosis after a first primary VTE and a trend towards an increased risk for males with recurrent primary VTE. This has not previously been shown. Ihaddadene et al. [17] found no association between sex and occult malignancy, Sørenssen et al. [10] found no particular gender difference and Trujillo-Santos et al. [15] found an odds ratio of 1.3 for male sex but did not reach significance. The explanation for the increased risk of a cancer diagnosis associated with male sex found here is not fully understood. One reason could be that there are other causes of venous thrombosis in women like pregnancy or hormonal treatment for which we lack information in our material. However, limiting our analysis to patients above 45 years of age where hormonally induced VTE in women is unlikely, male sex is still a strong risk factor for a subsequent cancer diagnose. One recent study [18] found an increased risk for first time VTE among men compared to females if female reproductive factors are taken into account. Here they discussed differences in genetic factors as one possible explanation. The increased risk of new cancer diagnosis among males identified in our study could be an alternative explanation for part of the higher risk of VTE associated with male sex.

Hypertension reduced the risk of a cancer diagnosis after a first VTE and there was a trend towards a reduced risk after a myocardial infarction in both first and recurrent 
VTE. Interestingly, Lind et al. [19] have published an increased prevalence of myocardial infarction after VTE, showing a link between cardiovascular disease and VTE risk. With cardiovascular disease as an alternate cause of VTE concurrent cancer might less often be the cause of VTE among these patients.

Dementia was shown to reduce the risk of a cancer diagnosis for a first but not for recurrent VTE. This may be due to a reluctance of physicians to search for malignancies in patients with severe dementia.

The most common type of cancer diagnosed after a recurrent VTE was in the male genitals with $23.8 \%$. Of these $96 \%$ were prostate cancers. Previous studies have shown a stronger correlation between prostate cancer and venous thrombosis compared to breast cancer [9], which could contribute to the risk increase for males.

With the high rate of cancer among VTE patients limited screening for occult cancer have been advised, including medical history, physical exam, basic bloodwork and chest radiograph. More extensive screening programs including CT scans or PET scans (fludeoxyglucose positron emission tomography) have not been found to be beneficial in identifying more occult cancers or reducing mortality [20-22] and is not advised as routine for all VTE patients.

\section{Limitations}

Using registers make the results dependant on the validity of data in the registers. The validity of the NPR has previously been shown to be good. In somatic care the register lacks information in only $0.5-0.9 \%$ of hospital admissions [23]. However, information about diagnoses from the primary health care is not included in the NPR, and therefore some concomitant diseases may have been underestimated. Cancer however is almost exclusively diagnosed and at least initially managed in specialised healthcare.

The inclusion of gender specific cancer complicates the analysis and may bias the results. However being a large proportion of all cancer the exclusion of gender specific cancer may also have created bias.

We also lack information about some factors that may influence both the cancer risk and risk for venous thrombosis like smoking, obesity and medical treatment. These could all be factors confounding the results. On the other hand, we here present a large real-life cohort of 7854 VTE patients corresponding to 14,284 observation years.

\section{Conclusion}

There is a substantial proportion of patients being diagnosed with cancer the first year after a primary VTE, anaemia and male sex confers an increased risk. Screening for cancer after a VTE has previously not been advised, but physicians caring for patients with VTE should be aware of symptoms and findings indicating occult cancer, especially among men and elderly without cardiovascular morbidity.

Author contribution AS and PJS designed the study. PS extracted and analysed the data. PS and AS drafted the manuscript. All authors critically reviewed the manuscript, contributed to its revision, and approved the final version submitted.

\section{Compliance with ethical standards}

Conflicts of interest None declared.

Ethical approval This study was approved by the regional ethical review board in Umeå, Sweden (EPN nr 2011-349-31 M and 2014-191-32 M) and conformed to the declaration of Helsinki.

Open Access This article is distributed under the terms of the Creative Commons Attribution 4.0 International License (http://crea tivecommons.org/licenses/by/4.0/), which permits unrestricted use, distribution, and reproduction in any medium, provided you give appropriate credit to the original author(s) and the source, provide a link to the Creative Commons license, and indicate if changes were made.

\section{Appendix}

\begin{tabular}{|c|c|}
\hline \multicolumn{2}{|l|}{ ICD-10 Codes } \\
\hline \multicolumn{2}{|c|}{ Background characteristics } \\
\hline Hypertension & I10-15 \\
\hline Cardiac failure & I50, I110, I130, I132 \\
\hline $\begin{array}{r}\text { Myocardial } \\
\text { infarction }\end{array}$ & $\mathrm{I} 21-22, \mathrm{I} 252$ \\
\hline Stroke/TIA & $\begin{array}{l}\text { I63-64, G450, G451, G452, G453, G458, } \\
\text { G459, I69 }\end{array}$ \\
\hline Diabetes & E10-14 \\
\hline Thyroid disorder & E00-E07 \\
\hline $\begin{array}{l}\text { Chronic } \\
\text { pulmonary } \\
\text { disease }\end{array}$ & $\mathrm{J} 40-70$ \\
\hline Dementia & F00-03 \\
\hline Anemia & $\begin{array}{l}\text { D50, D52, D53, D55, D59, D60, D61-D64, } \\
\text { D510, D513, D518, D519, D560-D562, } \\
\text { D568-D572, D588, D589. }\end{array}$ \\
\hline Major bleeding & $\begin{array}{l}\text { I60, I61, I62, R04, K250, K252, K254, K256, } \\
\text { K260, K262, K264, K266, K270, K272, } \\
\text { K274, K276, K280, K282, K284, K286, } \\
\text { K922, K290, I850, I983, K625, D629, R589 }\end{array}$ \\
\hline Renal failure & $\begin{array}{l}\text { I120, I131-132, N17-19, DR016, DR024, } \\
\text { KAS00, KAS10, KAS20 }\end{array}$ \\
\hline Liver failure & K70-77, JJC, JJB \\
\hline Cancer & $\mathrm{C} 00-\mathrm{C} 97$ \\
\hline
\end{tabular}




\section{References}

1. Heit JA, O'Fallon WM, Petterson TM, Lohse CM, Silverstein MD, Mohr DN, Melton LJ 3rd (2002) Relative impact of risk factors for deep vein thrombosis and pulmonary embolism: a population-based study. Arch Intern Med 162(11):1245-1248

2. Caine GJ, Stonelake PS, Lip GY, Kehoe ST (2002) The hypercoagulable state of malignancy: pathogenesis and current debate. Neoplasia 4(6):465-473. doi:10.1038/sj.neo.7900263

3. Khorana AA, Connolly GC (2009) Assessing risk of venous thromboembolism in the patient with cancer. J Clin Oncol 27(29):4839-4847. doi:10.1200/JCO.2009.22.3271

4. Langer F, Bokemeyer C (2012) Crosstalk between cancer and haemostasis. Implications for cancer biology and cancer-associated thrombosis with focus on tissue factor. Hamostaseologie 32(2):95-104. doi:10.5482/ha-1160

5. Sorensen HT, Svaerke C, Farkas DK, Christiansen CF, Pedersen L, Lash TL, Prandoni P, Baron JA (2012) Superficial and deep venous thrombosis, pulmonary embolism and subsequent risk of cancer. Eur J Cancer 48(4):586-593. doi:10.1016/j.ejca.2011.10. 032

6. Prandoni P, Falanga A, Piccioli A (2005) Cancer and venous thromboembolism. Lancet Oncol 6(6):401-410. doi:10.1016/ S1470-2045(05)70207-2

7. Otten HM, Prins MH (2001) Venous thromboembolism and occult malignancy. Thromb Res 102(6):V187-V194

8. Blom JW, Doggen CJ, Osanto S, Rosendaal FR (2005) Malignancies, prothrombotic mutations, and the risk of venous thrombosis. JAMA 293(6):715-722. doi:10.1001/jama.293.6.715

9. Levitan N, Dowlati A, Remick SC, Tahsildar HI, Sivinski LD, Beyth R, Rimm AA (1999) Rates of initial and recurrent thromboembolic disease among patients with malignancy versus those without malignancy. Risk analysis using medicare claims data. Medicine 78(5):285-291

10. Sorensen HT, Mellemkjaer L, Steffensen FH, Olsen JH, Nielsen GL (1998) The risk of a diagnosis of cancer after primary deep venous thrombosis or pulmonary embolism. N Engl J Med 338(17):1169-1173. doi:10.1056/NEJM199804233381701

11. UCR UCRC (2015) Auricula Annual Report 2013 [Auricula årsrapport 2013]. http://www.ucr.uu.se/auricula/index.php/arsrap porter. Accessed 26 Aug 2015

12. site TNBoHaWSw (2015) Swedish National Patient Register. http://www.socialstyrelsen.se/register/halsodataregister/patientre gistret/inenglish. Accessed 15 Nov 2015

13. Prandoni P, Lensing AW, Buller HR, Cogo A, Prins MH, Cattelan AM, Cuppini S, Noventa F, ten Cate JW (1992) Deep-vein thrombosis and the incidence of subsequent symptomatic cancer. $\mathrm{N}$ Engl J Med 327(16):1128-1133. doi:10.1056/NEJM199 210153271604
14. Sun LM, Chung WS, Lin CL, Liang JA, Kao CH (2016) Unprovoked venous thromboembolism and subsequent cancer risk: a population-based cohort study. J Thromb Haemost 14(3):495-503. doi:10.1111/jth.13251

15. Trujillo-Santos J, Prandoni P, Rivron-Guillot K, Roman P, Sanchez R, Tiberio G, Monreal M, Investigators R (2008) Clinical outcome in patients with venous thromboembolism and hidden cancer: findings from the RIETE registry. J Thromb Haemost 6(2):251-255. doi:10.1111/j.1538-7836.2007.02837.x

16. Khorana AA, Francis CW, Culakova E, Kuderer NM, Lyman GH (2007) Frequency, risk factors, and trends for venous thromboembolism among hospitalized cancer patients. Cancer 110(10):2339-2346. doi:10.1002/cncr.23062

17. Ihaddadene R, Corsi DJ, Lazo-Langner A, Shivakumar S, Zarychanski R, Tagalakis V, Solymoss S, Routhier N, Douketis J, Le Gal G, Carrier M (2016) Risk factors predictive of occult cancer detection in patients with unprovoked venous thromboembolism. Blood 127(16):2035-2037. doi:10.1182/blood2015-11-682963

18. Roach RE, Lijfering WM, Rosendaal FR, Cannegieter SC, le Cessie S (2014) Sex difference in risk of second but not of first venous thrombosis: paradox explained. Circulation 129(1):51-56. doi:10.1161/CIRCULATIONAHA.113.004768

19. Lind C, Flinterman LE, Enga KF, Severinsen MT, Kristensen SR, Braekkan SK, Mathiesen EB, Njolstad I, Cannegieter SC, Overvad K, Hansen JB (2014) Impact of incident venous thromboembolism on risk of arterial thrombotic diseases. Circulation 129(8):855-863. doi:10.1161/CIRCULATIONAHA.113.004168

20. Carrier M, Lazo-Langner A, Shivakumar S, Tagalakis V, Zarychanski R, Solymoss S, Routhier N, Douketis J, Danovitch K, Lee AY, Le Gal G, Wells PS, Corsi DJ, Ramsay T, Coyle D, Chagnon I, Kassam Z, Tao H, Rodger MA, Investigators S (2015) Screening for occult cancer in unprovoked venous thromboembolism. N Engl J Med 373(8):697-704. doi:10.1056/NEJM oa1506623

21. Robertson L, Yeoh SE, Stansby G, Agarwal R (2015) Effect of testing for cancer on cancer- and venous thromboembolism (VTE)-related mortality and morbidity in patients with unprovoked VTE. Cochrane Database Syst Rev. doi:10.1002/ 14651858.CD010837.pub2

22. Gheshmy A, Carrier M (2016) Venous thromboembolism and occult cancer: impact on clinical practice. Thromb Res 140(Suppl 1):S8-S11. doi:10.1016/S0049-3848(16)30091-3

23. Ludvigsson JF, Andersson E, Ekbom A, Feychting M, Kim JL, Reuterwall C, Heurgren M, Olausson PO (2011) External review and validation of the Swedish national inpatient register. BMC Public Health 11:450. doi:10.1186/1471-2458-11-450 